\title{
Survey of skin disorders in newborns: clinical observation in an Egyptian medical centre nursery
}

\author{
A.A. El-Moneim ${ }^{7}$ and R.E. El-Dawela ${ }^{2}$
}

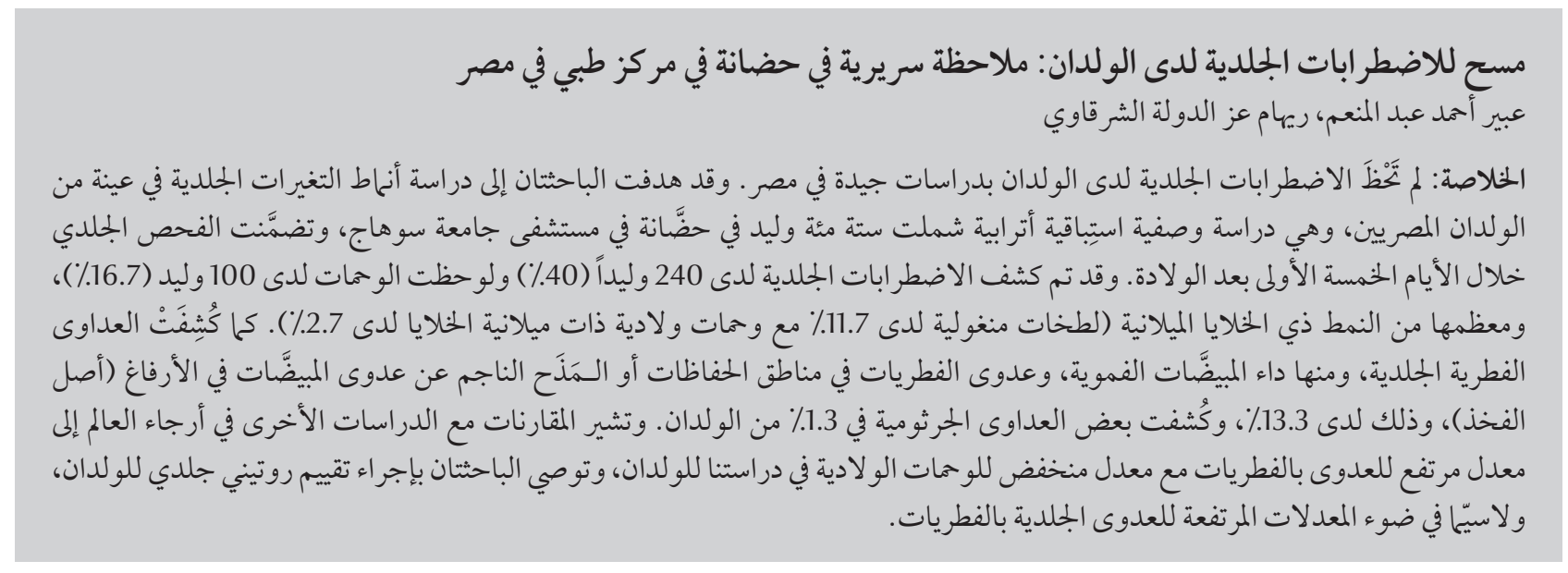

ABSTRACT The frequency of neonatal skin disorders has not been well studied in Egypt. Our aim was to address patterns of dermatological changes in a sample of Egyptian newborns. In a descriptive prospective cohort study 600 newborns in Sohag University hospital nursery were dermatologically examined within the first 5 days of birth. Skin disorders were detected in 240 neonates (40.0\%). Birthmarks were found in 100 neonates (16.7\%), mainly melanocytic type (mongolian spots in $11.7 \%$ and congenital melanocytic naevi in $2.7 \%$ ). Fungal skin infections, including oral moniliasis, fungal infection in the napkin area or candidal intertrigo, were detected in $13.3 \%$ and bacterial infections in $1.3 \%$ of neonates. Comparisons with other studies worldwide indicated a higher rate of fungal infections and lower rate of birthmarks in our study. Routine neonatal dermatological evaluation is recommended, especially in view of the high rate of fungal skin infections.

Étude sur les affections cutanées des nouveau-nés : observations cliniques dans un service pédiatrique égyptien

RÉSUMÉ La fréquence des affections cutanées chez les nouveau-nés n'a pas été étudiée de manière approfondie en Égypte. Notre objectif était d'effectuer une étude des altérations dermatologiques au sein d'un échantillon de nouveau-nés égyptiens. Dans une étude prospective descriptive d'une cohorte réalisée au service pédiatrique du centre hospitalier universitaire de Sohag, un examen dermatologique a été conduit sur 600 nouveau-nés au cours de leurs cinq premiers jours. Des affections cutanées ont été dépistées chez 240 d'entre eux (soit $40,0 \%$ de l'échantillon). Des naevi ont été observés chez 100 nouveau-nés (16,7 \%), principalement de type mélanocytaire (taches mongoliques pour 11,7 \% d'entre eux et nævi mélanocytaires congénitaux pour 2,7 \%). Des dermatomycoses, notamment une candidose buccale, une infection fongique du siège ou un intertrigo à Candida, ont été détectées chez 13,3\% des nouveau-nés, et 1,3\% présentaient des infections bactériennes. Par rapport à d'autres études dans le monde, le taux de dermatomycoses est élevé dans notre étude, alors que le taux de naevi est faible. Une évaluation dermatologique systématique est recommandée chez les nouveau-nés, compte tenu du taux élevé de dermatomycoses.

'Department of Paediatrics; ${ }^{2}$ Department of Dermatology, Venereology and Andrology, Sohag Faculty of Medicine; University of Sohag, Sohag, Egypt (Correspondence to A.A. El-Moneim: abeeraaa6@gmx.de).

Received: 03/11/09; accepted: 10/12/09 


\section{Introduction}

Neonatal skin provides physical protection and assists in fluid balance, immunosurveillance and thermoregulation, thus playing a vital role in the newborn's transition from an aqueous to an airdominant environment. A large number of changes from transient physiological to grossly pathological lesions are seen in the skin of a neonate [1]. The majority of the disorders in the newborn are physiological, transient and self-limited and require no therapy [2]. Worried parents often seek medical advice from their child's physician regarding skin lesions. Thus, a working knowledge of both normal and abnormal cutaneous lesions of the neonate is required to determine which skin lesions require early intervention.

Several studies have documented differences in dermatological findings in neonates of various racial groups. For example, the incidence of dermal melanosis is more common in black, native American, Asian and Hispanic populations [3]. Another study showed a higher prevalence of birthmarks in the Jewish than in the Arab Israeli population [4].

In this study in Sohag city in Egypt we recorded skin disorders in neonates during the first 5 days after birth. Our aim was to prospectively study the rate of skin disorders in a large group of Egyptian newborns, and their relation to sex, birth weight, sociodemographic factors and maternal pathophysiological variables. We also aimed to compare the findings with other studies from the literature among different racial and ethnic groups.

\section{Methods}

\section{Sample and setting}

This was descriptive prospective cohort study design in the neonatal unit at Sohag University hospital in Upper Egypt. This is a tertiary referral unit that serves around 2 million inhabitants living in Sohag province. The nursery capacity is 33 places. Outborn admissions represent about $75 \%$ of admissions to the nursery.

A total of 600 newborns in Sohag University hospital nursery during June 2008 to May 2009 were examined for skin problems. Consecutively admitted newborns over the period of the study were recruited if they were admitted in the first 5 days of life. During the study period 708 newborns were admitted. Of these 108 were excluded, due to age at admission above 5 days $(n=66)$, unavailability of the dermatologist before reaching 5 days of age $(n=31)$ or death before the dermatologist examination $(n=11)$.

\section{Data collection}

Each neonate was examined daily for 5 days after birth by the same examiner (R.E. El-D.) who was a consultant dermatologist. Using the International statistical classification of diseases and related health problems, version 10 (ICD 10) [5], all dermatological findings were noted, including transient benign lesions, pustular and vesicular infections, birthmarks (vascular and pigmented lesions), common congenital abnormalities, blistering disorders and other skin conditions. Fungal skin infections were confirmed by Wood light examination. Sex, birth weight and age in hours at the time of first examination were recorded. The examiner was blind to the sociodemographic, maternal or neonatal factors related to each neonate before or during clinical examination.

Relevant history was recorded, especially age of the mother, occupational, income and educational status, and rural or urban background of the parents. Parity of the mother, history of abortion, maternal illness or maternal smoking (passive and active) during pregnancy and the mode of delivery were noted.

The relationship between the frequency of lesions and various maternal and neonatal variables was studied. A comparison was made between low birth weight (LBW) $(<2500 \mathrm{~g})$ and normal birth weight (NBW) $(\geq 2500$ g) neonates.

\section{Ethical considerations}

Approval of Sohag Faculty of Medicine research ethics committee was sought before the start of the study. Written approval from the parents of each neonate was taken before the start of the clinical examination.

\section{Statistical analysis}

Data management and computations of descriptive statistics and prevalence were performed using SPSS for Windows, version 10. The chi-squared test was used to determine the significance of the association between the variables. Also, odds ratios (OR) at 95\% confidence interval (CI) were calculated to determine the strength of association. There were no missing data.

\section{Results}

Of 600 newborns, 240 (40.0\%) had 1 or more skin disorder at birth or that appeared during the first 5 days after birth.

\section{Description of skin disorders}

Birthmarks represented 100 (16.7\%) of the skin manifestations in the studied neonates. Pigmented naevi were the most common, with mongolian spots in $11.7 \%$ of neonates, followed by congenital melanocytic naevi (2.7\%). Vascular naevi included naevus simplex (1.3\%) and naevus flammeus (1.0\%) (Table 1).

Infections were the next most common type of skin disorder. Fungal skin infections were the most frequently observed pathological non-naevus skin disorder; 80 (13.3\%) of the examined neonates had either oral moniliasis, fungal infection in the napkin area or candidal intertrigo. Fungal infection was more frequent in NBW infants (7.8\%) than in LBW infants (5.5\%) (Table 2). 


\begin{tabular}{|c|c|c|}
\hline Skin disorder & No. & $\%$ \\
\hline \multicolumn{3}{|l|}{ Pigmented birthmarks } \\
\hline Mongolian spots & 70 & 11.7 \\
\hline Congenital melanocytic naevi & 16 & 2.7 \\
\hline \multicolumn{3}{|l|}{ Vascular birthmarks } \\
\hline Naevus simplex (salmon patches) & 8 & 1.3 \\
\hline Naevus flammeus (portwine patches) & 6 & 1.0 \\
\hline \multicolumn{3}{|l|}{ Infections } \\
\hline Fungal & 80 & 13.3 \\
\hline Bacterial & 8 & 1.3 \\
\hline \multicolumn{3}{|l|}{ Eczema } \\
\hline Contact allergic dermatitis & 24 & 4.0 \\
\hline Perianal dermatitis (non-infected) & 4 & 0.7 \\
\hline Infantile seborrhoeic dermatitis (cradle cap) & 24 & 4.0 \\
\hline \multicolumn{3}{|l|}{ Transient non-infective skin diseases } \\
\hline Miliaria rubra (prickly heat) & 10 & 1.7 \\
\hline Erythema toxicum & 8 & 1.3 \\
\hline Miliaria pustulosa & 7 & 1.2 \\
\hline \multicolumn{3}{|l|}{ Physiological skin changes } \\
\hline Desquamation & 80 & 13.3 \\
\hline $\begin{array}{l}\text { Congenital hypertrichosis lanuginosa (lanugo hair)/ } \\
\text { hirsuitism }\end{array}$ & 74 & 12.4 \\
\hline Cutis marmorata & 32 & 5.3 \\
\hline Milia & 18 & 3.0 \\
\hline \multicolumn{3}{|l|}{ Developmental skin defects } \\
\hline Congenital fossae (skin dimples) & 26 & 4.3 \\
\hline Accessory tragus (skin tags) & 21 & 3.5 \\
\hline \multicolumn{3}{|l|}{ Other } \\
\hline Bronze discolouration (after phototherapy) & 16 & 2.7 \\
\hline Epidermolysis bullosa & 12 & 2.0 \\
\hline Disseminated intravascular coagulation & 9 & 1.5 \\
\hline Thrombophlebitis & 7 & 1.2 \\
\hline Purpura fulminans & 4 & 0.7 \\
\hline Collodion baby & 3 & 0.5 \\
\hline Ichthyosis & 1 & 0.2 \\
\hline
\end{tabular}

Bacterial infections were found in 1.3\% of neonates and were more common in LBW $(0.8 \%)$ than in NBW $(0.5 \%)$ (Table 2).

Among skin disorders classified as physiological, desquamation was seen in $13.3 \%$ of neonates and congenital hypertrichosis lanuginosa in $11.7 \%$ (57.1\% of them were delivered by normal vaginal delivery and $80 \%$ of them were from non-smoking mothers). Infantile seborrhoeic dermatitis was found in $4.0 \%$
(90.0\% and 62.5\% respectively) (Table 2), but neither was related to maternal age or to maternal smoking. Among developmental skin defects congenital fossae were the most common (4.3\%), followed by accessory tragi (3.5\%). Among the other types of skin changes, bronze baby syndrome and epidermolysis bullosa were found in $2.7 \%$ and $2.0 \%$ respectively of our sample.

\section{Characteristics of neonates with skin disorders}

Our analysis showed no major differences in the rate of skin disorders between the sexes: 121 cases were in males (50.4\%) and 119 in females (49.6\%). Skin disorders were found in 151 newborns $(62.9 \%)$ of multigravida mothers and 89 (37.1\%) of primigravida mothers. More than half of mothers (129, $53.8 \%)$ were in the age group 21-25 years, $57(23.8 \%)$ were aged $\leq 20$ years old and 54 (22.5\%) were aged 26-40 years.

Analysis of the characteristics of neonates with infectious skin lesions versus those with non-infectious skin lesion are summarized in Table 3. A significant positive association was found between infectious skin changes and normal birth weight of the newborns, with low birth weight infants less likely to have skin disorders ( $\mathrm{OR}=0.3,95 \%$ CI: $0.2-0.5, P<0.001)$. Fungal infections were more frequent in NBW neonates $(58.8 \%)$ while bacterial infections were more frequent in LBW (62.5\%) (Table 2). No significant association was found between maternal smoking and infectious skin changes in neonates. Mothers living in rural areas were more likely to have newborns with infectious skin lesions ( $\mathrm{OR}=2.6,95 \% \mathrm{CI}$ : 1.6-4.2, $P<0.001)$; $87.5 \%$ of neonates with bacterial infections and $66.2 \%$ of neonates with fungal infections were resident in rural areas.

Analysis of the characteristics of neonates with and without birthmarks are summarized in Table 4. Birthmarks were significantly more common in 


\begin{tabular}{|c|c|c|c|c|}
\hline \multirow[t]{3}{*}{ Skin lesion } & \multicolumn{4}{|c|}{ Neonatal birth weight } \\
\hline & \multicolumn{2}{|c|}{ Normal } & \multicolumn{2}{|c|}{ Low } \\
\hline & No. & $\%$ & No. & $\%$ \\
\hline \multicolumn{5}{|l|}{ Pigmented birthmarks } \\
\hline Mongolian spots & 69 & 98.6 & 1 & 1.4 \\
\hline Congenital melanocytic naevi & 7 & 43.8 & 9 & 56.2 \\
\hline \multicolumn{5}{|l|}{ Vascular birthmarks } \\
\hline Naevous simplex (salmon patches) & 3 & 37.5 & 5 & 62.5 \\
\hline $\begin{array}{l}\text { Naevous flammeus (portwine } \\
\text { patches) }\end{array}$ & 5 & 83.3 & 1 & 16.7 \\
\hline \multicolumn{5}{|l|}{ Infections } \\
\hline Bacterial & 3 & 37.5 & 5 & 62.5 \\
\hline Fungal & 47 & 58.8 & 33 & 41.2 \\
\hline \multicolumn{5}{|l|}{ Eczema } \\
\hline $\begin{array}{l}\text { Infantile seborrhoeic dermatitis } \\
\text { (cradle cap) }\end{array}$ & 17 & 70.8 & 7 & 29.2 \\
\hline Contact allergic dermatitis & 5 & 20.8 & 19 & 79.2 \\
\hline \multicolumn{5}{|l|}{ Transient non-infective skin diseases } \\
\hline Miliaria rubra & 9 & 90.0 & 1 & 10.0 \\
\hline Erythema toxicum neonatorum & 5 & 62.5 & 3 & 37.5 \\
\hline \multicolumn{5}{|l|}{ Physiological changes } \\
\hline Desquamation & 53 & 66.2 & 27 & 33.8 \\
\hline $\begin{array}{l}\text { Congenital hypertrichosis lanuginosa } \\
\text { (lanugo hair) }\end{array}$ & 41 & 55.4 & 33 & 44.6 \\
\hline Cutis marmorata & 4 & 12.5 & 28 & 87.5 \\
\hline Milia & 13 & 72.2 & 5 & 27.8 \\
\hline \multicolumn{5}{|l|}{ Other } \\
\hline Bronze discolouration & 16 & 100.0 & 0 & 0.0 \\
\hline Epidermolysis bullosa & 4 & 33.3 & 8 & 66.7 \\
\hline
\end{tabular}

full-term infants with normal birth weight compared with low birth weight infants (OR $=0.1,95 \%$ CI: $0.07-0.24, P$ $<0.001$ ). Mongolian spots and naeveus fllammeus were more frequent in NBW neonates. Congenital melanocytic naevi and naeveus simplex were more common in LBW (Table 2). Sex did not increase the risk for birthmarks $(P$ $=0.5$ ) but living in a rural area increased the risk of birthmarks in newborns (OR $=2.5,95 \%$ CI: $1.5-3.9, P<0.001)$.

\section{Discussion}

A critical step in neonatal examination is differentiating normal skin phenomena reported to be $49.7 \%$ while in those of Jewish origin the incidence was $50.3 \%$ [4]. In India the incidence of birthmarks was found to be $69 \%$ [7]

Melanocytic (pigmented) birthmarks were more frequent than vascular ones in our study and the most common pigmented birthmarks were mongolian spots in 70 neonates, a frequency of $11.7 \%$. The rate of mongolian spots was higher in NBW neonates. Congenital melanocytic naevi were the second most common pigmented birthmarks with a frequency of $2.7 \%$ and their incidence was higher in LBW neonates. Vascular birthmarks were less common; naevus simplex (salmon patches) and naevus flammeus (portwine patches) were found in $1.3 \%$ and $1.0 \%$ of neonates respectively. Naevus flammeus were common in NBW neonates while naevus simplex were common in LBW neonates. No haemangiomas were recorded in our study.

Vascular birthmarks such as naevus flammeus and haemangiomas were the most common birthmarks in German neonates with a frequency of $37.2 \%$ [8]. Pigmented birthmarks were also the most frequent skin manifestation in Iranian neonates with a frequency of mongolian blue spots of $71.3 \%$, while salmon patches were less frequent $(26.2 \%)$ and haemangiomas were the least frequent (1.3\%) [6]. In Taiwan, mongolian blue spots were the most common birthmarks with a frequency of $61.6 \%$, followed by salmon patches $27.8 \%$. Haemangiomas and congenital naevi were found in only $0.2 \%$ and $0.6 \%$ of neonates respectively [9]. Similarly, mongolian spots and salmon patches were the most common birthmarks in Chinese neonates with a frequency of $86.3 \%$ and $22.6 \%$ respectively, while portwine patch, salmon patches and congenital naevi were the least frequent [10]. In Arab and Jewish infants of Asian or African ancestry, melanocytic brown lesions (mongolian spots and congenital naevi) were more common, while congenital naevi were found only in 


\begin{tabular}{|c|c|c|c|c|c|c|}
\hline \multirow[t]{3}{*}{ Characteristic } & \multicolumn{4}{|c|}{ Infectious skin lesion } & \multirow[t]{3}{*}{ OR $(95 \% \mathrm{Cl})$} & \multirow[t]{3}{*}{$P$-value } \\
\hline & \multicolumn{2}{|c|}{$\begin{array}{c}\text { Yes } \\
(\boldsymbol{n}=\mathbf{8 8})\end{array}$} & \multicolumn{2}{|c|}{$\begin{array}{c}\text { No } \\
(n=384)\end{array}$} & & \\
\hline & No. & $\%$ & No. & $\%$ & & \\
\hline \multicolumn{7}{|c|}{ Neonatal birth weight } \\
\hline Low & 38 & 43.2 & 280 & 72.9 & - & \\
\hline Normal & 50 & 56.8 & 104 & 27.1 & $0.3(0.2-0.5)$ & $<0.001$ \\
\hline \multicolumn{7}{|c|}{ Maternal smoking } \\
\hline Yes & 40 & 45.5 & 305 & 79.4 & - & \\
\hline No & 48 & 54.5 & 79 & 20.6 & $0.2(0.1-0.4)$ & $<0.001$ \\
\hline \multicolumn{7}{|c|}{ Maternal residency } \\
\hline Rural & 60 & 68.2 & 174 & 45.3 & - & \\
\hline Urban & 28 & 31.8 & 210 & 54.7 & $2.6(1.6-4.2)$ & $<0.001$ \\
\hline
\end{tabular}

$O R=$ odds ratio $; C l=$ confidence interval.

Jewish infants of European ancestry [4]. Our results suggest that the prevalence of birthmarks in Egyptian neonates is similar to its prevalence reported by others in non-white infants (Arabs, Asians and Africans).

Fungal skin infection was the most frequently observed pathologic nonnaevous neonatal skin disorder in our study; 80 (13.3\%) of the examined neonates had either oral moniliasis, fungal infection in the napkin area or candidal intertrigo. The incidence of fungal skin infection in our study was greater than that observed in other studies where it ranged from $2 \%$ to $7 \%$
$[1,2,5-7]$. Interestingly, it was more common in neonates with NBW than in LBW neonates. Besides, fungal skin infection was related to residence in a rural area (in $63 \%$ of fungal-infected neonates the mother resided in a rural area), but it had no relationship to maternal antibiotic therapy before delivery (in $68.4 \%$ of fungal-infected neonates the mother did not receive antibiotics before delivery).

Physiological skin changes were also among the more frequent skin manifestations in our studied neonates, with skin desquamation the most common (13.3\%). It was more common in males than females and among term babies. The incidence of skin desquamation in other studies varied from $7.2 \%$ to $83 \%[11,12]$. These variations may be attributed to the fact that the babies in other studies were followed up for more than 5 days.

Congenital hypertrichosis lanuginosa (lanugo hair) was seen in 70 cases (11.7\%), a finding that is comparable to the incidence in other studies $[8,9,11]$. Predictably, a high percentage of them were preterm (59\%) infants. Lanugo hair was also common in normal vaginal deliveries and was not related to maternal smoking.

\begin{tabular}{|c|c|c|c|c|c|c|}
\hline \multirow[t]{3}{*}{ Characteristic } & \multicolumn{4}{|c|}{ Birthmarks } & \multirow[t]{3}{*}{ OR $(95 \% \mathrm{Cl})$} & \multirow[t]{3}{*}{$P$-value } \\
\hline & \multicolumn{2}{|c|}{$\begin{array}{c}\text { Yes } \\
(n=100)\end{array}$} & \multicolumn{2}{|c|}{$\begin{array}{c}\text { No } \\
(n=498)\end{array}$} & & \\
\hline & No. & $\%$ & No. & $\%$ & & \\
\hline \multicolumn{7}{|c|}{ Neonatal birth weight } \\
\hline Low & 16 & 16.0 & 290 & 58.2 & - & \\
\hline Normal & 84 & 84.0 & 208 & 41.8 & $0.1(0.07-0.24)$ & $<0.001$ \\
\hline \multicolumn{7}{|l|}{ Sex } \\
\hline Male & 54 & 54.0 & 287 & 57.6 & - & \\
\hline Female & 46 & 46.0 & 211 & 42.4 & $0.9(0.6-1.3)$ & 0.5 \\
\hline \multicolumn{7}{|c|}{ Maternal residency } \\
\hline Rural & 70 & 70.0 & 243 & 48.8 & - & \\
\hline Urban & 30 & 30.0 & 255 & 51.2 & $2.5(1.5-3.9)$ & $<0.001$ \\
\hline
\end{tabular}

$O R=$ odds ratio; $C l=$ confidence interval. 
Infantile seborrhoeic dermatitis (cradle cap) was seen in 24 cases (4.0\%) in our study. In Germany it was $8.2 \%$ [8], in Italy $10.7 \%$ [11] and in Taiwan it was $6.1 \%$ [9]. This low incidence, as compared with other studies, may be due to small sample size in our study $[8,9,11]$. Its incidence was low in LBW neonates.

Cutis marmorata was seen in 32 cases $(5.3 \%)$ in our study and most of the cases were of LBW. This incidence was comparable to that reported in other studies $[6,9,13]$.

Milia was seen in 18 neonates (3.0\%) in this study. It was common in term babies and had no relation to maternal factors. This rate was lower than reported in India (8.3\%) [13], the Islamic Republic of Iran (6.2\%) [6] and Taiwan (4.5\%) [9].

Eczematous skin eruption was common in our study, with a frequency of contact dermatitis of $4.0 \%$. This was more common in LBW neonates and was related to maternal passive smoking.

Bronze baby syndrome and epidermolysis bullosa were also relatively common in our sample with a frequency of $2.7 \%$ and $2.0 \%$ respectively. This incidence was comparable to that reported in other studies $[12,14,15]$. In our study all bronze baby syndrome cases had birth weight $>2500 \mathrm{~g}$ while most epidermolysis bullosa cases were in LBW neonates.
Developmental skin defects were common in our study. Congenital fossae (skin dimples) was the most common with a frequency of $4.3 \%$, followed by accessory tragi (skin tags) with a frequency of $3.5 \%$. This incidence is different from other studies where there was a lower incidence of skin tragi (1.3\%) [8] and higher incidence of hirsutism [7].

Transient non-infective skin diseases were uncommon in our study. The most frequent was miliaria rubra with a frequency of $1.7 \%$, followed by erythema toxicum neonatorum with a frequency of $1.3 \%$. These showed no relation to maternal factors but they were common in full term neonates and in neonates with birth weight $>2500$ g. This incidence was lower than other studies where the incidence of erythema toxicum neonatorum varied between $11.1 \%$ and $33.7 \%$ and miliaria rubra between $1.3 \%$ and $20.6 \%[7,8,11]$. These variations in incidence may be related to racial differences as these disorders are common in Asian races but not in Caucasian or Arab races [2].

Previous studies found racial variations in skin changes in newborns. Salmon patches and mongolian spots were the most common birthmarks in non-white Asian and Arab neonates while congenital naevi were common in white and European neonates [6,810]. Similarly, erythema toxicum was the most common non-birthmark skin change in non-white Asian neonates but was the least frequent in European (German) neonates [6,8]. Our results support these racial variations as the frequencies of birthmarks, transient skin lesions, and developmental defects reported in our Egyptian neonates were lower than those reported in other studies.

\section{Conclusions}

Skin changes in this sample of Egyptian neonates differ from the results of studies in other races, with a higher rate of fungal infection and lower rate of birthmarks. Most skin lesions in the newborn are innocent and transient and need to be differentiated from more serious skin conditions in order to avoid unnecessary therapy to neonates and to reassure parents about the good prognosis of these skin manifestations.

\section{Acknowledgements}

This work was presented as a poster in the 50th meeting of the European Society of Paediatric Research on 9-12 October 2009 in Hamburg, Germany and was published as an abstract in Acta Paediatrica, 2009, 98(Suppl. 460):69.

\section{References}

1. O'Connor NR, McLaughlin MR, Ham P. Newborn skin: Part I. Common rashes. American Family Physician, 2008, 77:47-52.

2. Atherton J. The neonate. In: Rook A, Wilkinson S, Ebling G, eds. Textbook of dermatology, 6th ed. Oxford, Blackwell Science, 1998:449-518.

3. Jacobs AH, Walton RG. The incidence of birthmarks in the neonate. Pediatrics, 1976, 58:218-222.

4. Kahana $\mathrm{M}$ et al. The incidence of birthmarks in Israeli neonates. International Journal of Dermatology, 1995, 34:704-706.

5. International statistical classification of diseases and health related problems, 10th revision. Volume 2. Geneva, World Health Organization, 1993.

6. Moosavi Z, Hosseini T. One-year survey of cutaneous lesions in 1000 consecutive Iranian newborns. Pediatric Dermatology, 2006, 23:61-63.
7. Sachdeva M et al. Cutaneous lesions in new born. Indian Journal of Dermatology, Venereology and Leprology, 2002, 68:334-337.

8. Lorenz $\mathrm{S}$ et al. Hautveranderungen bei Neugeborenen in den ersten 5 Lebenstagen [Skin changes in newborn infants in the first 5 days of life]. Der Hautarzt, 2000, 51:396-400.

9. Shih $\mathrm{IH}$ et al. A birthmark survey in 500 newborns: clinical observation in two northern Taiwan medical center nurseries. Chang Gung Medical Journal, 2007, 30:220-225.

10. Tsai FJ, Tsai CH. Birthmarks and congenital skin lesions in Chinese newborns. Journal of the Formosan Medical Association, 1993, 92:838-841.

11. Boccardi $D$ et al. Birthmarks and transient skin lesions in newborns and their relationship to maternal factors: a preliminary report from northern Italy. Dermatology (Basel, Switzerland), 2007, 215:53-58. 
12. Dash $\mathrm{K}$ et al. Clinicoepidemiological study of cutaneous manifestations in the neonate. Indian Journal of Dermatology, Venereology and Leprology, 2000, 66:26-28.

13. Mishra PC, Mathur GP, Mathur S. Normal anatomic variants in the newborn. Indian Pediatrics, 1992, 22:39-42.

14. Rivers JK, Frederiksen PC, Dibdin C. A prevalence survey of dermatoses in the Australian neonate. Journal of the American Academy of Dermatology, 1990, 23:77-81.
15. Saraeli T, Kenney JA, Scott RB. Common skin disorders in the newborn Negro infant. Observations based on the examination of 1000 babies. Journal of Pediatrics, 1963, 63:358-362.

\section{CDROM Publications of the Regional Office for the Eastern Mediterranean. 26 Years of Health Knowledge}

This CD includes a fully searchable bibliographic database with off-line access to the full text of 634 publications of the WHO Regional Office for the Eastern Mediterranean, published between 1985 and 2010. This digital library brings together 26 years of Regional Office health information products, some of which are no longer available in print. It covers 75 health topics related to the major health issues in the Region and includes in monographs, training materials, technical documents, reports, guidelines, and advocacy publications in Arabic, English and French. The aim of this series is to improve the accessibility and availability of regional health information products for all health workers, researchers and professionals of the health sector.

Further information about this and other WHO publications is available at: http://www.who.int/publications/en/ 